\title{
Chromatic dispersion analysis and compensation in a large core-count few-mode multi-core fiber based on optical vector network analysis
}

\author{
Citation for published version (APA): \\ van Weerdenburg, J., Rommel, S., Delgado Mendinueta, J. M., Klaus, W., Sakaguchi, J., Vegas Olmos, J. J., \\ Koonen, T., Awaji, Y., Tafur Monroy, I., Okonkwo, C., \& Wada, N. (2019). Chromatic dispersion analysis and \\ compensation in a large core-count few-mode multi-core fiber based on optical vector network analysis. In 2019 \\ Optical Fiber Communications Conference and Exhibition, OFC 2019 - Proceedings [8696547] Optical Society of \\ America (OSA). https://doi.org/10.1364/OFC.2019.M1E.2
}

DOI:

10.1364/OFC.2019.M1E.2

Document status and date:

Published: 22/04/2019

\section{Document Version:}

Accepted manuscript including changes made at the peer-review stage

\section{Please check the document version of this publication:}

- A submitted manuscript is the version of the article upon submission and before peer-review. There can be important differences between the submitted version and the official published version of record. People interested in the research are advised to contact the author for the final version of the publication, or visit the DOI to the publisher's website.

- The final author version and the galley proof are versions of the publication after peer review.

- The final published version features the final layout of the paper including the volume, issue and page numbers.

Link to publication

\footnotetext{
General rights

- You may freely distribute the URL identifying the publication in the public portal. follow below link for the End User Agreement:

www.tue.nl/taverne

\section{Take down policy}

If you believe that this document breaches copyright please contact us at:

openaccess@tue.nl

providing details and we will investigate your claim.
}

Copyright and moral rights for the publications made accessible in the public portal are retained by the authors and/or other copyright owners and it is a condition of accessing publications that users recognise and abide by the legal requirements associated with these rights.

- Users may download and print one copy of any publication from the public portal for the purpose of private study or research.

- You may not further distribute the material or use it for any profit-making activity or commercial gain

If the publication is distributed under the terms of Article $25 \mathrm{fa}$ of the Dutch Copyright Act, indicated by the "Taverne" license above, please 


\title{
Chromatic Dispersion Analysis and Compensation in a Large Core-Count Few-Mode Multi-Core Fiber Based on Optical Vector Network Analysis
}

\author{
John van Weerdenburg ${ }^{(1)}$, Simon Rommel ${ }^{(1)}$, José Manuel Delgado Mendinueta ${ }^{(2)}$, \\ Werner Klaus $^{(2)}$, Jun Sakaguchi ${ }^{(2)}$, Juan José Vegas Olmos ${ }^{(3)}$, Ton Koonen ${ }^{(1)}$, \\ Yoshinari Awaji $^{(2)}$, Idelfonso Tafur Monroy ${ }^{(1)}$, Chigo Okonkwo ${ }^{(1)}$, and Naoya Wada ${ }^{(2)}$ \\ ${ }^{(1)}$ Institute for Photonic Integration, Eindhoven University of Technology, $5600 \mathrm{MB}$ Eindhoven, the Netherlands \\ ${ }^{(2)}$ Photonic Network System Laboratory, National Institute of Information and Communication Technology (NICT), \\ 4-2-1 Nukui-Kitamachi, Koganei, Tokyo 184-8795, Japan \\ ${ }^{(3)}$ Mellanox Technologies, Ledreborg Allé 130B, 4000 Roskilde, Denmark \\ j.j.a.v.weerdenburg@tue.nl
}

\begin{abstract}
Chromatic dispersion in a large core-count 3-mode fiber is analyzed, observing up to $0.75 \mathrm{ps} /(\mathrm{nm} \cdot \mathrm{km})$ variations between mode groups. Furthermore, digital CD compensation is shown to relax the stringent path length matching required in such systems.
\end{abstract}

OCIS codes: 120.3180 Interferometry, 060.2270 Fiber Characterization, 060.4230 Multiplexing

\section{Introduction}

Space division multiplexing (SDM) has been widely proposed to meet the increasing demand for capacity in optical communication systems. Total transmission capacities beyond $10 \mathrm{~Pb} / \mathrm{s}$ have been recently demonstrated [1], enabled by the spatial multiplexing among the combination of modes and cores. Key to unlocking the full potential of SDM systems is a comprehensive understanding of the properties of the transmission fiber and other system components in order to optimize their design and the digital signal processing (DSP) required to compensate any signal impairments. The impulse response and frequency dependent behavior of these components can be described by a complex transfer matrix, which can be measured using a spatially-diverse optical vector network analyzer (OVNA) based on sweptwavelength interferometry (SWI) [2,3]. From this transfer matrix, all linear device parameters, including insertion loss (IL) and mode dependent loss (MDL), can be derived. Recently, this measurement technique has been used to analyze the modal dispersion and group delay in large core-count few-mode fiber [4,5]. Significant variations between mode and mode group delays where observed based on impulse response measurements.

In this work, the wavelength dependency of the impulse response is investigated to compare the group delay and chromatic dispersion (CD) between the cores. For each core, a positive and negative differential CD value is observed by independent evaluation of the two mode groups. Differential CD, compared to a single-mode (SM) core, varies between $-2.9 \mathrm{ps} / \mathrm{nm}$ to $-0.1 \mathrm{ps} / \mathrm{nm}$, and $0.6 \mathrm{ps} / \mathrm{nm}$ to $6.9 \mathrm{ps} / \mathrm{nm}$ for the two mode groups respectively between the few-mode cores. These variations between the cores show high correlation with the total impulse response duration. Furthermore, partial CD compensation has been applied to improve the representation and accuracy of impulse response measurements obtained from OVNAs for fibers and components with large differential CD.

\section{Optical Vector Network Analyzer for SDM components}

SWI has been proven to be a powerful technique to obtain the $2 \times 2$ Jones matrix of single-mode fiber (SMF) components over a large wavelength range in a relatively fast and simple measurement. In a spatially diverse OVNA, this principle is extended to support the larger dimensions of the transfer matrix of SDM components. Fig. 1 depicts the 3-mode OVNA setup employed to characterize a few-mode multi-core fiber (FM-MCF) span of $13.6 \mathrm{~km}$ and two glass inscribed mode multiplexers. The 39-core fiber [5] consists of a three-ring structure with 383 -mode cores and one single-mode core (Fig. 2a). The output of a C-band laser, continuously swept at a rate of $100 \mathrm{~nm} / \mathrm{s}$, is fed to an interferometric structure where one arm contains a device under test (DUT) and the other acts as a reference. As in conventional single-mode SWI, a time delay between the two states of polarization is introduced by a polarization multiplexing stage. Subsequently, time delays are introduced for all ports of the mode-(de)multiplexers. Note that it 


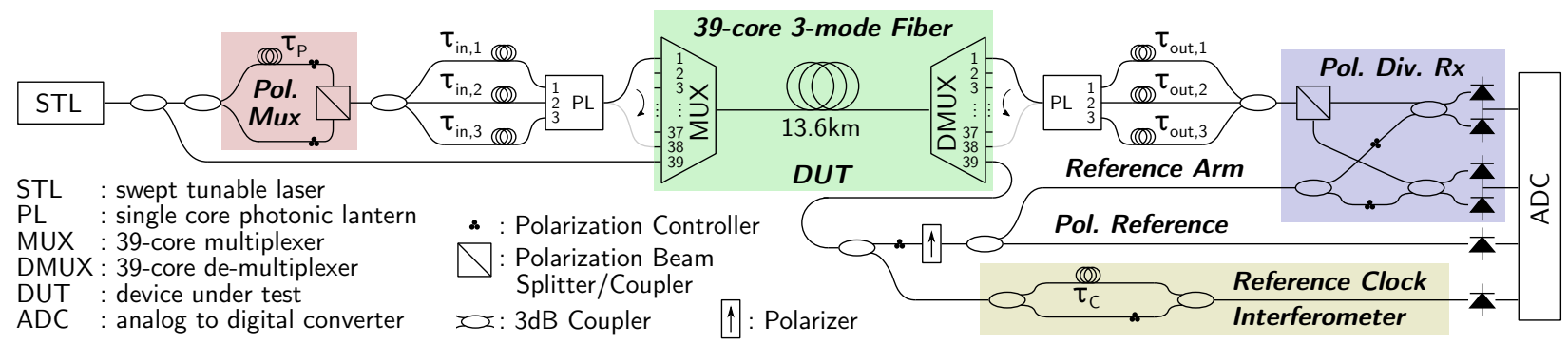

Fig. 1. Spatially diverse optical vector network analyzer setup configured for multi-core 3-mode fiber analysis.

is important to choose the delays such that all 36 elements of the $6 \times 6$ transfer matrix $H(\omega)$ of a single 3-mode core have an unique value and the minimum difference is large enough to accommodate the expected spread in impulse response introduced by the DUT. The SM core of the FM-MCF serves as the reference arm of this interferometer and is branched into two. One arm is polarized and serves as a reference in a polarization diverse detector, where it is combined with the measurement arm. The electrical output of the balanced photo-diodes is digitized by an analogto-digital converter (ADC) sampling at $10 \mathrm{MS} / \mathrm{s}$. A copy of the polarized reference is digitized with a single-ended photo-diode and used to track wavelength dependent polarization changes in the reference arm. The second arm of the reference signal is fed to an additional interferometer with delay $\tau_{c}$, which is employed as a clock to compensate for deviations in the sweep rate of the laser source and linearize the wavelength sweep in terms of frequency.

In the digital domain, a band-pass filter is applied to the reference clock signal prior to extraction of sample points. These sample points, linear in frequency, are used to re-sample the two measurement channels of the receiver. In the re-timed spectra all elements of the DUT $h_{i j}(t)$ response are separated according to the chosen delays $\tau_{\text {in }}, \tau_{\text {out }}$, and $\tau_{\mathrm{p}}$, and can be selected with a windowing function. By taking the FFT of the complex impulse response $h(t)$, the DUT $H(\omega)$ can be obtained. Performing a singular value decomposition (SVD) on $H(\omega)$ result in device parameters IL and MDL. The group delays $\tau_{\mathrm{g}}$ can be found from the principle states of polarization found by an eigenvalue analysis on $H(\omega+\delta \omega) H(\omega)^{-1}[4,6]$ or by estimation on $h(t)$.

\section{Few-mode multi-core fiber analysis}

The transfer matrix for all 39 cores is measured sequentially and ranging from $1530 \mathrm{~nm}$ to $1570 \mathrm{~nm}$, resulting in a $6 \times 6$ complex matrix for each core. These 36 elements can be summed in power to a reduced impulse response representation making comparison between cores more comprehensible. From this simplified representation, the total impulse response and modal dispersion can be extracted. The total impulse response duration ranges from $0.6 \mathrm{~ns}$ to $3.0 \mathrm{~ns}$ and varies strongly per core, as can be seen in Fig. 2b [4].

To visualize the frequency and temporal behavior simultaneously, a spectrogram can be generated for each of the 36 elements of every core. In the same manner as for the impulse response, these plots can be collapsed to a single graph for each core, making visual comparison easier. The spectrogram for core 1, depicted in Fig. 2e, clearly shows the two mode groups within the 3-mode core. The group in the bottom half of the graph contains two closely spaced spectral lines. This small offset between the lines can most likely be attributed to a difference in propagation speed of the two polarization states within the $\mathrm{LP}_{01}$ mode in combination with minor errors occurring in the windowing process. The spread of energy in the upper part of the spectrogram indicates stronger modal dispersion, which is to be expected for the 4 non-degenerate polarization modes within the $\mathrm{LP}_{11}$ group.

Furthermore, all spectral lines appear to change linearly with wavelength, but with a different slope, indicating variance in differential $\mathrm{CD}$ between the mode groups. With straight-forward curve fitting, the $\mathrm{CD}$ values for the two groups can be estimated to be $-2.4 \mathrm{ps} / \mathrm{nm}$ for $\mathrm{LP}_{01}$ and $4.2 \mathrm{ps} / \mathrm{nm}$ for $\mathrm{LP}_{11}$, respectively. Fig. $2 \mathrm{~d}$ shows the estimated $\mathrm{CD}$ for the two mode groups within all 38 few-mode (FM) cores, SM core 39, and a reference SMF link of similar length. For all few-mode cores, the fundamental mode shows slightly lower dispersion values compared to the SM core and SMF link, whereas dispersion of the other mode group show stronger variations with a higher CD average. The increased deviation is related to the larger impulse response spread caused by mode dispersion.

As CD is a linear transmission impairment, it can easily be compensated in DSP by applying an equally large complementary amount of wavelength-dependent dispersion. With the estimated dispersion slope, CD of a single mode group can be fully compensated for, as can be seen in Fig. $2 \mathrm{f}$ and Fig. $2 \mathrm{~g}$, where digital CD compensation is applied on $H(\omega)$. Alternatively, an intermediate CD value can be chosen to partially compensate both groups simultaneously.

Since the SM core is used as a reference, the amount of differential CD observed with the OVNA is relatively low. 
a)
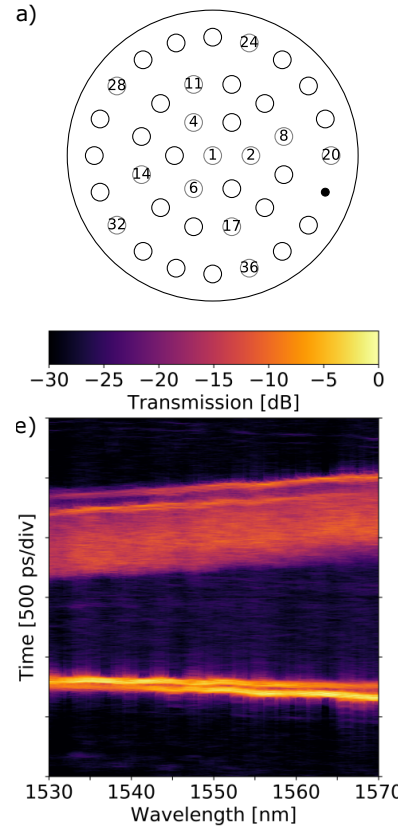

b)
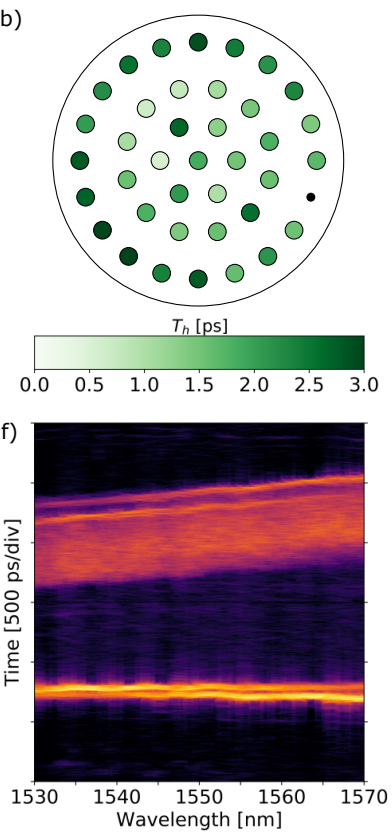

c)
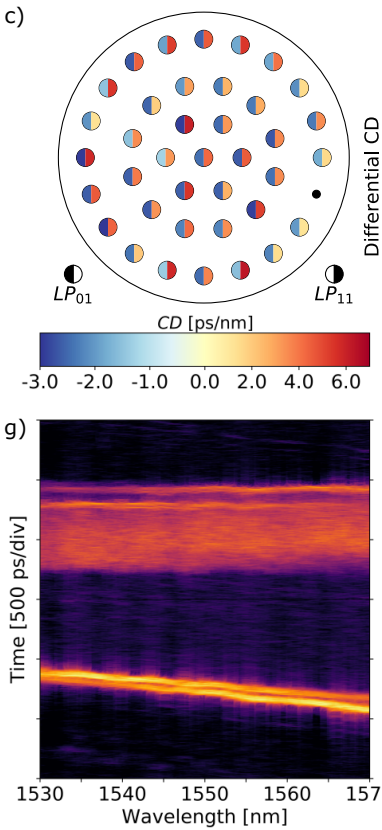
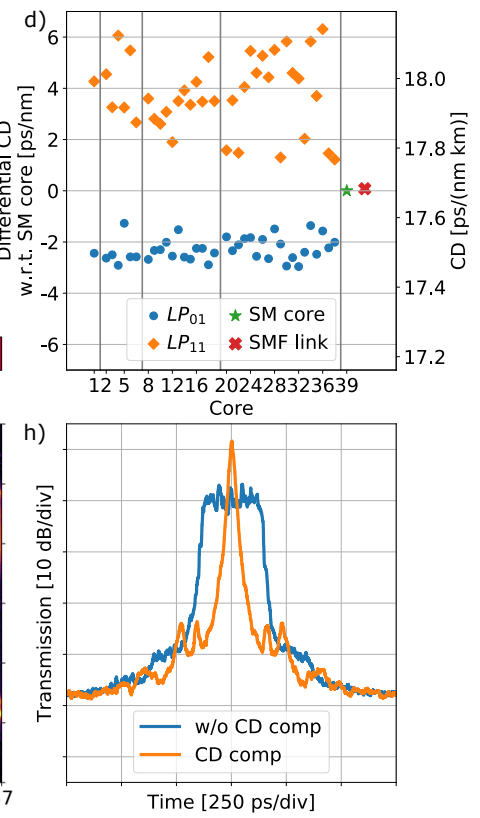

Fig. 2. a) Core labeling of the few-mode multi-core fiber. Total impulse response duration (b) and differential CD (c) of each core. d) Differential to single-mode core and absolute CD for FM-MCF and SMF. Spectrograms for core 1: e) no CD compensation, compensated for $-2.4 \mathrm{ps} / \mathrm{nm}$ (f), and $4.3 \mathrm{ps} / \mathrm{nm}$ (g) of differential CD. h) Summed impulse response of the SM core before and after CD compensation.

However, generally, a separate SMF link is employed in OVNA measurements and exactly matching the lengths of DUT and reference is challenging and commonly a mismatch remains. In order to characterize the SM core within the FM-MCF, a SMF link has been used. From optical time domain reflectometry (OTDR) measurements a $46 \mathrm{~m}$ difference between the SM core of the FM-MCF and the SMF link is measured. In combination with the large wavelength range, this small difference can build up rapidly to large amounts of CD. Fig. $2 \mathrm{~h}$ shows the sum of the $2 \times 2$ impulse response of the SM core before and after CD compensation. Alternatively, digital CD compensation can also be applied directly after re-timing, simplifying the placement of the windows in the transfer function extraction stage.

\section{Conclusions}

In this work, chromatic dispersion (CD) of a 39-core 3-mode few-mode multi-core fiber (FM-MCF) has been analyzed based on optical vector network analyzer (OVNA) measurements. Large variations in CD among the few-mode cores is observed and found to show strong correlation with the total impulse response duration observed in previous measurements. CD is found to vary significantly (up to $0.75 \mathrm{ps} /(\mathrm{nm} \cdot \mathrm{km})$ ) between mode groups and partial separate compensation for non-overlapping modes has been shown. Furthermore, CD compensation in an OVNA has been applied on a single-mode core, relaxing the requirement of matching arm lengths within such measurement systems.

Acknowledgments This work was partially funded by the the Dutch NWO Graduate Photonics program (GA no. 022.005.011) and the blueSPACE project (GA no. 762055) which has received funding from the European Union's Horizon2020 research and innovation programme.

\section{References}

[1] D. Soma et al., "10.16 peta-bit/s dense SDM/WDM transmission over low-DMD 6-mode 19-core fibre across C+L band," in Proc. European Conf. Optical Commun. (ECOC), paper Th.PDP.A.1, 2017

[2] N.K. Fontaine et al., "Characterization of space-division multiplexing systems using a swept-wavelength interferometer," in Proc. Optical Fiber Commun. Conf. (OFC), paper OW1K.2, 2013

[3] S. Rommel et al., "Few-mode fiber, splice and SDM component characterization by spatially-diverse optical vector network analysis," Optics Express, vol. 25, no.19, pp. 22347, 2017

[4] S. Rommel et al.," "Measurement of Modal Dispersion and Group Delay in a Large Core Count Few-Mode Multi-Core Fiber," in Proc. European Conf. Optical Commun. (ECOC), paper Tu1E.2, 2018

[5] J. Sakaguchi et al., "228-spatial-channel Bi-directional Data Communication System Enabled by 39-core 3-mode Fiber," in Proc. European Conf. Optical Commun. (ECOC), paper Mo3G.1, 2018

[6] B.L. Heffner et al., "Accurate, automated measurement of differential group delay dispersion and principal state variation using Jones matrix eigenanalysis," Photon. Technol. Lett., vol. 5, no.7, pp. 814-817, 1993 